\title{
Embolization by micro navigation for treatment of persistent type 2 Endoleaks after endovascular abdominal aortic aneurysm repair
}

\section{Embolização por micronavegação para tratamento de Endoleak tipo 2 persistente após reparo endovascular do aneurisma de aorta abdominal}

\author{
Bruno Lorenção de Almeida', Antônio Massamitsu Kambara' ${ }^{1}$, Fabio Henrique Rossi', \\ Marcelo Bueno de Oliveira Colli', Eduardo Silva Jordão de Oliveira', Patrick Bastos Metzger', \\ Camila Baumann Beteli', Sthefanie Fauve Andrade Cavalcante ${ }^{2}$
}

\begin{abstract}
Background: Endovascular repair has become established as a safe and effective method for treatment of abdominal aortic aneurysms. One major complication of this treatment is leakage, or endoleaks, of which type 2 leaks are the most common. Objective: To conduct a brief review of the literature and evaluate the safety and effectiveness of embolization by micronavigation for treatment of type 2 endoleaks. Method: A review of medical records from patients who underwent endovascular repair of abdominal aortic aneurysms identified 5 patients with persistent type 2 endoleaks. These patients were submitted to embolization by micronavigation. Results: In all cases, angiographic success was achieved and control CT scans showed absence of type 2 leaks and aneurysm sacs that had reduced in size after the procedure. Conclusion: Treatment of type 2 endoleaks using embolization by micronavigation is an effective and safe method and should be considered as a treatment option for this complication after endovascular repair of abdominal aortic aneurysms.
\end{abstract}

Keywords: abdominal aortic aneurysm; endoleak; embolization.

\begin{abstract}
Resumo
Contexto: O reparo endovascular se estabeleceu como uma modalidade segura e efetiva no tratamento do Aneurisma de Aorta Abdominal. Uma das principais complicações deste tipo de tratamento é o Vazamento ou Endoleak, sendo o do tipo 2 o mais frequente deles. Objetivo: Fazer uma breve revisão de literatura e avaliar a segurança e a efetividade da embolização por micronavegação para o tratamento do Vazamento tipo 2. Método: A revisão dos prontuários dos pacientes submetidos ao Reparo Endovascular do Aneurisma de Aorta abdominal identificou cinco pacientes que apresentavam Endoleak tipo 2 persistente. Esses pacientes foram submetidos à embolização por micronavegação. Resultado: Em todos os casos, houve sucesso angiográfico e as tomografias de controle evidenciavam ausência de Vazamento tipo 2 e diminuição do saco aneurismático, após o procedimento. Conclusão: $\mathrm{O}$ tratamento do Endoleak tipo II por embolização por micronavegação é um método efetivo e seguro, sendo considerado uma opção para esta complicação após o Reparo Endovascular do Aneurisma de Aorta Abdominal.
\end{abstract}

Palavras-chave: aneurisma de aorta abdominal; vazamento; embolização.

IInstituto Dante Pazzanese de Cardiologia - IDPC, São Paulo, SP, Brazil. ${ }^{2}$ Hospital Beneficência Portuguesa de São Paulo, São Paulo, SP, Brazil. Financial support: None.

Conflicts of interest: No conflicts of interest declared concerning the publication of this article

Submitted: 03.22.14. Accepted: 05.22.14. 


\section{INTRODUCTION}

Endovascular repair has become established as a safe and effective treatment for abdominal aortic aneurysms. One of the principal complications of this type of treatment is leaks, or endoleaks, defined as persistence of blood flow inside the aneurysm sac, in other words, outside of the lumen of the endoprosthesis. ${ }^{1-3}$

Leaks can be classified into five types, the most common of which is type 2. A type 2 leak is the result of retrograde flow into the aneurysm sac from aortic branches and as such is unrelated to the prosthesis itself. The natural history of this type of endoleak is still uncertain and both the appropriate time for treatment and the management approach itself are debatable, since up to $50 \%$ of cases undergo spontaneous resolution. However, persistent type 2 leaks (duration $>6$ months) and leaks associated with increased in aneurysm sac size are generally treated because they are linked with adverse events. Techniques that have been described in the literature include arterial ligature, employing open surgery or laparoscopy, and embolization accomplished via transabdominal or translumbar puncture or by micronavigation. ${ }^{4}$

The objective of this article is to present a brief review of the literature and to evaluate the safety and efficacy of embolization by micronavigation for treatment of type 2 leaks.

\section{METHODS}

A review was conducted of medical records from patients who had undergone endovascular abdominal aortic aneurysm repair at the Instituto Dante Pazzanese de Cardiologia between January and December 2012. Five patients were identified who had exhibited a persistent type 2 endoleak for more than 6 months during follow-up. At this point the decision was taken to attempt invasive treatment of the leaks, as recommended in current literature and with the objective of avoiding complications caused by persistent blood flow into the aneurysm sac. Technical success was defined as absence of leakage shown by a control angiography at the end of the procedure. Treatment success was defined as absence of leakage for at least 6 months shown by control tomographic examinations.

\section{RESULTS}

Four male patients and three female patients with ages varying from 61 to 85 were treated. The following prostheses were employed for endovascular aneurysm repair: two Talent prostheses (Medtronic), one Anaconda prosthesis (Terumo), one Zenith prosthesis (Cook) and one Excluder prosthesis (Gore).

Three-dimensional reconstructions of the most recent angiotomographies were consulted and leaks were confirmed by selective angiographic examinations for all patients. Although this procedure increases the risk of complications related to employing iodinated contrast, it enables better planning of the intervention, including definition of the materials and techniques to be used, thereby reducing complications related to the procedure and increasing the likelihood of success. The arteries identified on imaging exams as being responsible for leaks were the inferior mesenteric artery in two cases, the lumbar arteries in two cases and the branch of the superior gluteal artery in one case.

Prior to their procedures, all patients underwent clinical assessment and the risks and benefits of the treatment were explained to them before they signed consent forms. For all patients, the procedure started with puncture of the most appropriate common femoral artery for accessing the target vessel, followed by placement of a valved introducer using the Seldinger technique. The access vessel was then selectively catheterized using a diagnostic catheter over a $0.035^{\prime}$ hydrophilic guide wire; where the target was the inferior mesenteric, the superior mesenteric artery was selected, whereas the internal iliac artery was used to access the lumbar and gluteal arteries. The introducer was changed for a $45 \mathrm{~cm}$ Destination 6F (Terumo) sheath over a 0.035 ' rigid guide wire and then micronavigation was initiated with a $130 \mathrm{~cm}$, 2.4F Progreat (terumo) catheter.

After reaching the artery responsible for leakage, the microcatheter was advanced up to the origin inside the aneurysm, thereby enabling embolization not only of the target artery, but also of the central point of leakage inside the aneurysm sac. The concern with embolization of the artery and of the central point of leakage is due to the fact that this space created by the blood flow could be a predisposing factor for further leaks, because of the difference in pressure compared to the other branch coming from the aneurysm sac.

The embolization material used in all cases was an oil-based iodinated contrast medium (Lipiodol - Guerbet) combined with n-Butyl cyanoacrylate monomer tissue adhesive (Histoacryl - B.Braun), which polymerizes rapidly on contact with blood. Care must be taken when handling these materials because n-Butyl cyanoacrylate also polymerizes 
rapidly on contact with the ions in saline solutions. One should therefore only employ glucose solution during the procedure. Additionally, injection of the embolic material should be accompanied by a rapid backward movement of the microcatheter, to avoid its distal extremity becoming glued to the embolization site. The lumen of the microcatheter should also be swiftly washed with glucose solution to avoid it becoming obstructed by remnants of embolic material.

In all cases, angiographic success was achieved and control tomographies for all patients showed an absence of the type 2 leak and reduction in aneurysm sac size. Figure 1 shows an initial outpatients followup tomography for one of the patients and Figures 2, $3,4,5$ and 6 show the procedure step-by-step. Figure 7 shows confirmation of treatment success.

\section{DISCUSSION}

Endoleaks are a common complication of Endovascular Abdominal aortic aneurysm repair (EVAR), affecting around 15 to $40 \%$ of patients who undergo this treatment. Type 2 endoleaks are the most common and can account for up to $30 \%$ of all leaks. ${ }^{1-3}$

The mechanism by which Type 2 endoleaks are formed is still not clear. After EVAR, a communication is formed between arterial branches that come from the territory that was operated on, such as the inferior mesenteric and/or lumbar branches. Generally, one of the branches is the source of the leak, which drains via one or more of the other branches, thereby closing a circuit of perpetual blood flow through the aneurysm sac. This mechanism is dependent of local factors of vascular resistance, interarterial connections and other factors that have not yet been fully explained. ${ }^{4,5}$

The natural history of this type of endoleak is controversial and the great majority follow a benign course, resolving spontaneously during follow-up. Malignity, coronary disease and chronic obstructive pulmonary disease are linked with high rates of spontaneous closure. Up to $55 \%$ of cases in which leaks persist for more than 6 months are associated with growth in aneurysm sac size. However, aneurysm rupture related to this type of leak is rare, occurring in just 2 to $6 \%$ of cases. ${ }^{6}$

It is because of all of these reasons that the ideal approach to management of type 2 endoleaks is still a controversial subject. Some authors are in favor of intervention for all persistent leaks that last for more than 6 months, irrespective of whether the aneurysm sac has expanded. The reasons given for choosing this early intervention option are the risk of continued growth and rupture, the risk of aortic remodeling, leading to the emergence of other leaks (types 1 or 3 ), and the need for repeated follow-up examinations using contrast tomography. ${ }^{7}$ However, there are other authors who are not in favor of immediate treatment, arguing that the majority of type 2 leaks resolve spontaneously, with rates of around $50 \%$ at 6 months. Additionally, the costs and risks imposed by radiographic follow-up are very often less than those associated with early intervention. ${ }^{7-9}$ In our sample of

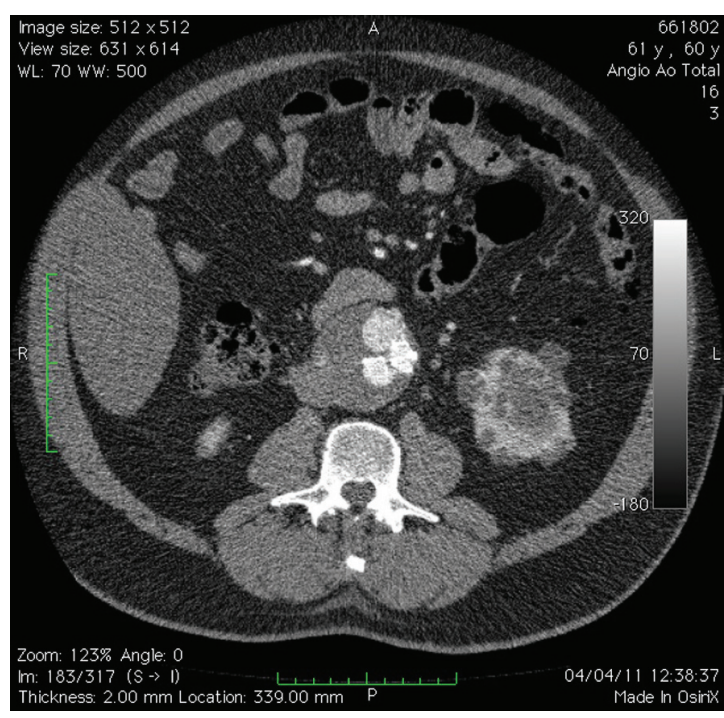

Figure 1. Computed tomography showing type 2 endoleak via the inferior mesenteric artery. Contrast can be seen outside of the endoprosthesis lumen and within the aneurysm sac.

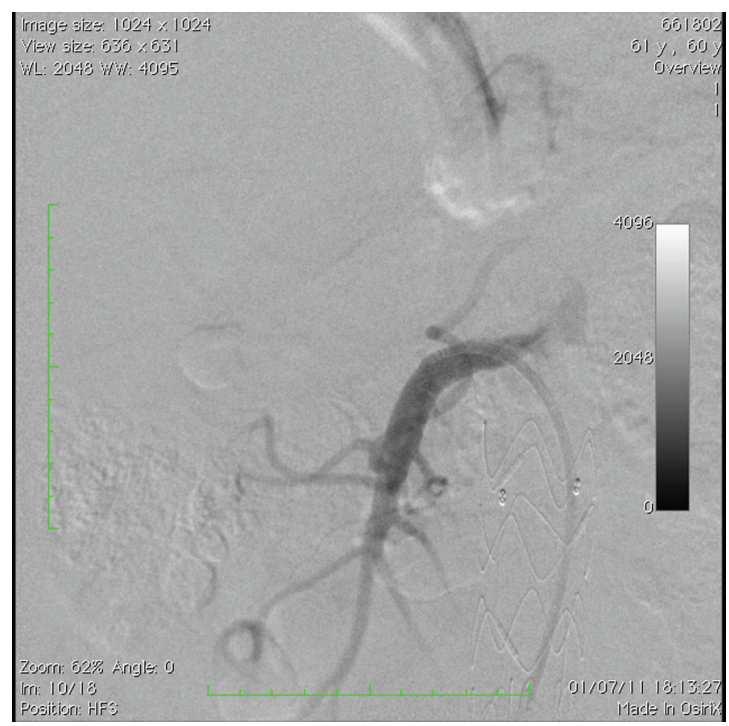

Figure 2. Endovascular access to the superior mesenteric artery. 


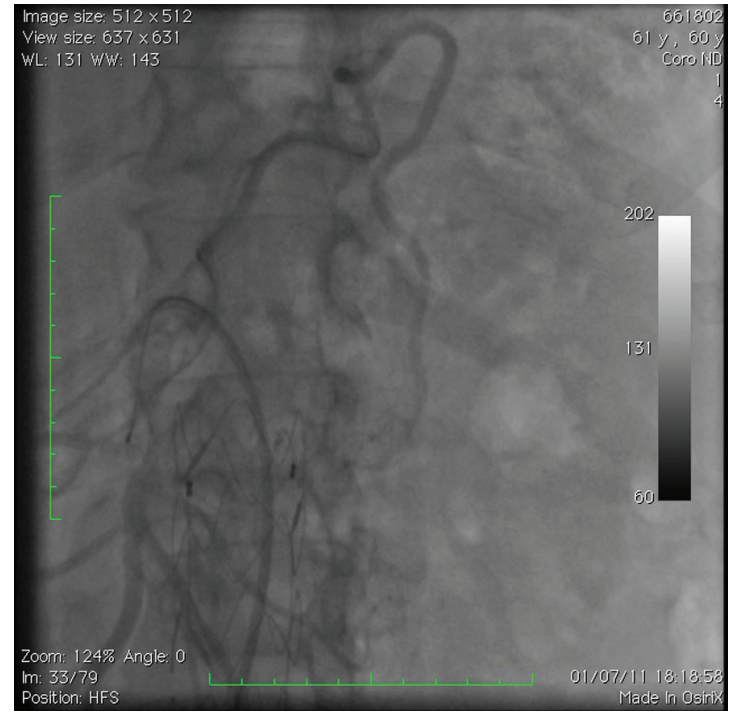

Figure 3. Micronavigation via the arc of Riolan to the inferior mesenteric artery.

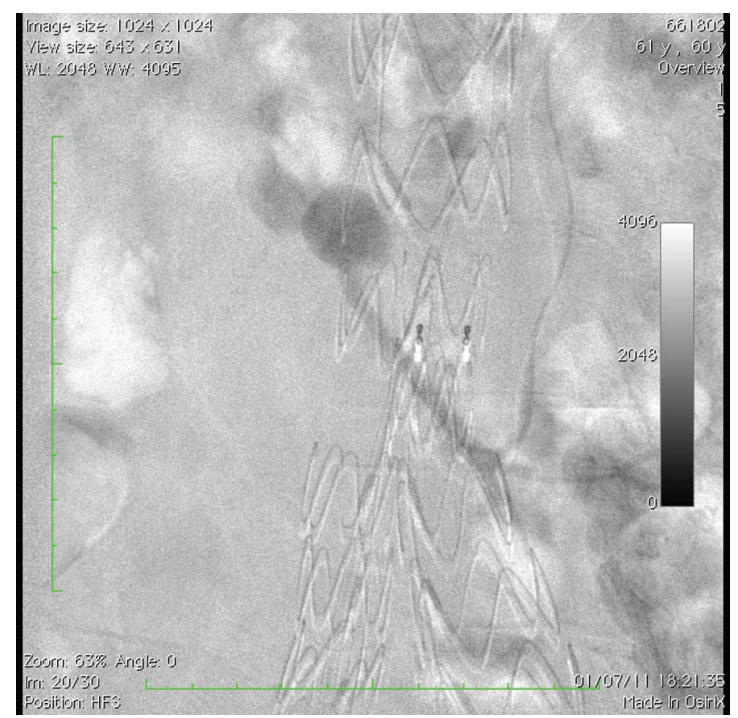

Figure 4. Confirmation of leakage by iodinated contrast injection.

patients, treatment was only conducted on patients whose type 2 leaks had remained for more than 6 months, irrespective of growth in aneurysm sac size.

Of the many approaches described in the literature, the endovascular approach has been the most studied and is widely used, because of its low invasivity and good efficacy and safety. Other treatment possibilities for type 2 leaks include ligature of branches using open or laparoscopic surgery and embolization of the aneurysm sac by direct puncture guided by

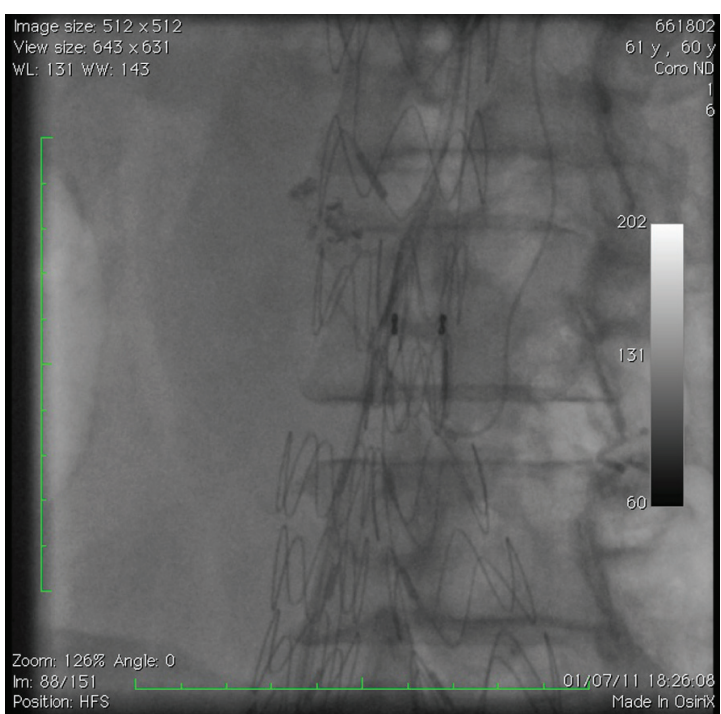

Figure 5. Injection of embolic material to the central point of leakage and the ostium of the artery responsible for leakage.

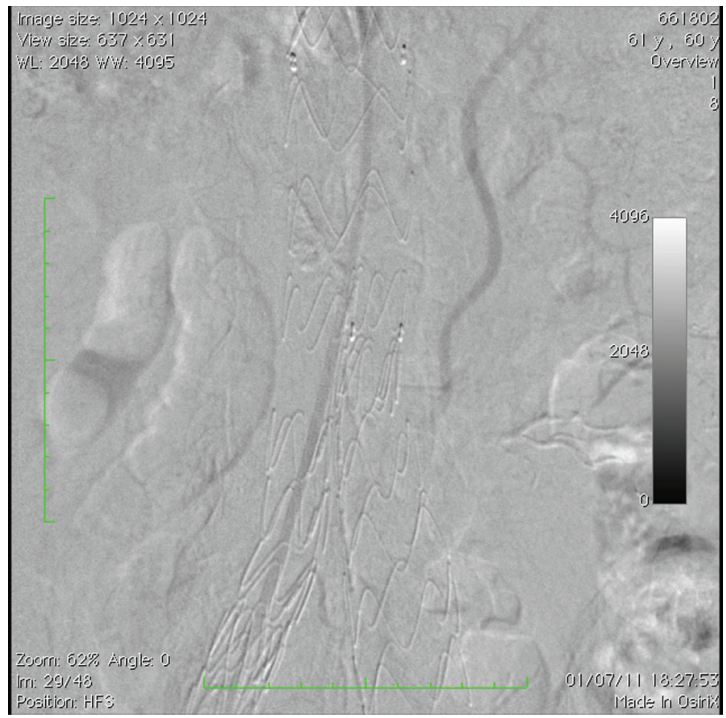

Figure 6. Angiographic confirmation of successful embolization.

tomography. These methods are basically employed in cases for which micronavigation is unsuccessful or unavailable. There are many reports in the literature attesting to the efficacy of laparoscopic methods for ligature of the inferior mesenteric artery and the lumbar arteries. Combination laparoscopic and endovascular methods have also been described. ${ }^{10-12}$ Transabdominal or translumbar approaches are also possible and the choice depends on whether the leak in the aneurysm sac is located anteriorly or 


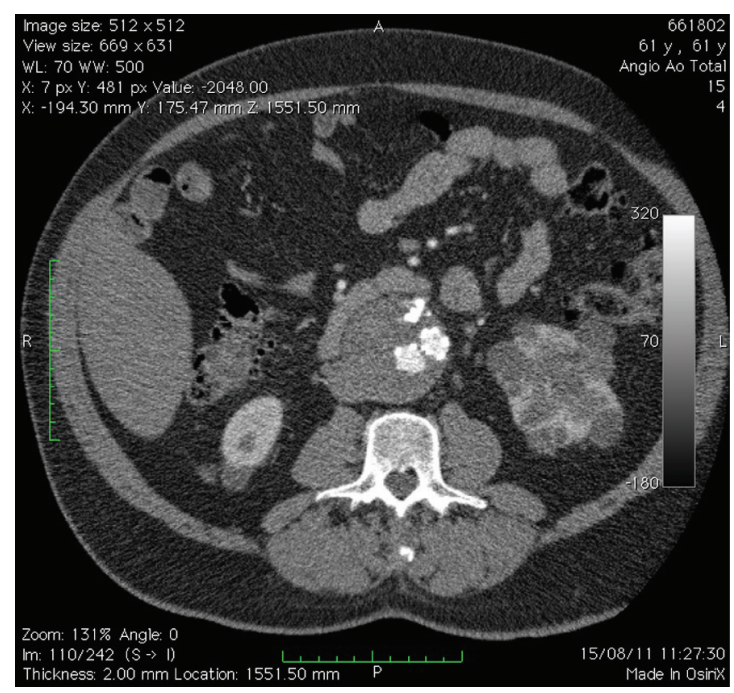

Figure 7. Follow-up computed tomography showing treatment success. The iodine-impregnated embolic material can be seen inside the aneurysm sac.

posteriorly. Auxiliary techniques such as fluoroscopy and ultrasonography may also be employed..$^{13}$ The sigmoid and transverse colons can be made to stand out using barium, helping to guide puncture. One of the greatest advantages of this method is direct embolization of the central point of leakage, thereby avoiding recruitment of new vessels. Baum et al. have shown that patients who were subjected to embolization of the primary branch of the leakage only, using endovascular approaches, were more susceptible to recurrence, probably due to development of collateral circulation by recruitment of other branches. This mechanism can therefore be compared to a vascular malformation, in which only treatment of the nidus (i.e. embolization of the central point of the leakage within the aneurysm sac) is truly effective to prevent recurrence. ${ }^{14,15}$ This is the procedure that was employed with the patients described here, whose control examinations show the embolic material filling the aneurysm sac. ${ }^{16}$

After embolization, patients must still be followedup with care, even after treatment success, since some will continue to exhibit aneurysm sac growth. Sarac et al. ${ }^{17}$ have shown that patients who smoke are more susceptible to aneurysm sac growth, even after effective embolization of type 2 leaks. Additionally, other types of leakage involving aortic remodeling can emerge, whether secondary to placement of the endoprosthesis or related to disease developing proximal or distal of the repair.

\section{CONCLUSIONS}

Treatment of type 2 leaks using embolization by micronavigation is an effective and safe method and should be considered as an option for treating this complication of endovascular abdominal aortic aneurysm repair. However, its use requires sufficient training in advanced endovascular techniques. More studies are needed in order to better elucidate the pathophysiology and natural history of type 2 leaks and also to define precise criteria for indicating invasive treatment or radiological monitoring.

\section{REFERENCES}

1. Parry DJ, Kessel DO, Robertson I, et al. Type II endoleaks: predictable, preventable, and sometimes treatable? J Vasc Surg. 2002;36(1):105-10. http://dx.doi.org/10.1067/mva.2002.125023. PMid:12096266

2. Chernyak V, Rozenblit AM, Patlas $M$, et al. Type II endoleak after endoaortic graft implantation: diagnosis with helical CT arteriography. Radiology. 2006;240(3):885-93. http://dx.doi. org/10.1148/radiol.2403051013. PMid:16868280

3. Aun R, Saes GF, Tachibana A, et al. Growth of abdominal aortic aneurysm after endoluminal repair. J Vasc Bras. 2004;3(4):387-91.

4. Baum RA, Carpenter JP, Tuite CM, et al. Diagnosis and treatment of inferior mesenteric arterial endoleaks after endovascular repair of abdominal aortic aneurysms. Radiology. 2000;215(2):40913. http://dx.doi.org/10.1148/radiology.215.2.r00ma17409. PMid:10796917

5. Baum RA, Carpenter JP, Golden MA, et al. Treatment of type 2 endoleaks after endovascular repair of abdominal aortic aneurysms: comparison of transarterial and translumbar techniques. J Vasc Surg. 2002;35(1):23-9. http://dx.doi. org/10.1016/S0741-5214(02)32021-4. PMid:11802129

6. Jonker FH, Aruny J, Muhs BE. Management of type II endoleaks: preoperative versus postoperative versus expectant management. Semin Vasc Surg. 2009;22(3):165-71. http://dx.doi.org/10.1053/j. semvascsurg.2009.07.008. PMid:19765527

7. Jones JE, Atkins MD, Brewster DC, et al. Persistent type 2 endoleak after endovascular repair of abdominal aortic aneurysm is associated with adverse late outcomes. J Vasc Surg. 2007;46(1):1-8. http://dx.doi.org/10.1016/j.jvs.2007.02.073. PMid:17543489

8. Higashiura W, Greenberg RK, Katz E, Geiger L, Bathurst S. Predictive factors, morphologic effects, and proposed treatment paradigm for type II endoleaks after repair of infrarenal abdominal aortic aneurysms. J Vasc Interv Radiol. 2007;18(8):975-81. http:// dx.doi.org/10.1016/j.jvir.2007.05.019. PMid:17675614

9. Steinmetz E, Rubin BG, Sanchez LA, et al. Type II endoleak after endovascular abdominal aortic aneurysm repair: a conservative approach with selective intervention is safe and cost-effective. J Vasc Surg. 2004;39(2):306-13. http://dx.doi.org/10.1016/j. jvs.2003.10.026. PMid:14743129

10. Ho P, Law WL, Tung PH, Poon JT, Ting AC, Cheng SW. Laparoscopic transperitoneal clipping of the inferior mesenteric artery for the management of type II endoleak after endovascular repair of an aneurysm. Surg Endosc. 2004;18(5):870. http://dx.doi. org/10.1007/s00464-003-4258-1. PMid:15216873

11. Feezor RJ, Nelson PR, Lee WA, Zingarelli W, Cendan JC. Laparoscopic repair of a type II endoleak. J Laparoendosc Adv 
Surg Tech A. 2006;16(3):267-70. http://dx.doi.org/10.1089/ lap.2006.16.267. PMid:16796438

12. Karkos CD, Hayes PD, Lloyd DM, et al. Combined laparoscopic and percutaneous treatment of a type II endoleak following endovascular abdominal aortic aneurysm repair. Cardiovasc Intervent Radiol. 2005;28(5):656-60. http://dx.doi.org/10.1007/ s00270-004-0120-7. PMid:16010514

13. Choi SY, Won JY, Lee Y, Choi D, Shim WH, Lee KH. Percutaneous transabdominal approach for the treatment of endoleaks after endovascular repair of infrarenal abdominal aortic aneurysm. Korean J Radiol. 2010;11(1):107-14. http://dx.doi.org/10.3348/ kjr.2010.11.1.107. PMid:20046501

14. Kasirajan K, Matteson B, Marek JM, Langsfeld M. Technique and results of transfemoral superselective coil embolization of type II lumbar endoleak. J Vasc Surg. 2003;38(1):61-6. http://dx.doi. org/10.1016/S0741-5214(02)75467-0. PMid:12844090

15. Wilmot A, Stavropoulos SW. Embolization of a recurrent type 2 endoleak using the liquid embolic n-Butyl cyanoacrylate. Semin Intervent Radiol. 2007;24(1):38-42. http://dx.doi. org/10.1055/s-2007-971187. PMid:21326734

16. Bailey MA, McPherson SJ, Troxler MA, Peach AH, Patel JV, Scott DJ. Ischemic skin ulceration complicating glue embolization of type II endoleak after endovascular aneurysm repair. J Vasc Interv Radiol. 2011;22(2):163-7. http://dx.doi.org/10.1016/j.jvir.2010.10.018. PMid:21276913

17. Sarac TP, Gibbons C, Vargas L, et al. Long-term follow-up of type II endoleak embolization reveals the need for close surveillance. J Vasc Surg. 2012;55(1):33-40. http://dx.doi.org/10.1016/j. jvs.2011.07.092. PMid:22056249
Correspondence Bruno Lorenção de Almeida Avenida Chibarás, 290/182 CEP 04076-000 - Moema (SP), Brazi E-mail: brunolorencao@gmail.com

Author information

BLA, FHR, MBOC and ESJO - Primary physicians, Endovascular Intervention Center (CIEV), Instituto Dante Pazzanese de Cardiologia

(IDPC).

AMK - Head of the Radiology Section, Instituto Dante Pazzanese de Cardiologia (IDPC)

PBM and CBB - Primary physicians, Vascular Ultrasound, Instituto Dante Pazzanese de Cardiologia (IDPC).

SFAC - General surgeon, Hospital Beneficência Portuguesa de São Paulo.

Author contributions Conception and design: BLA Analysis and interpretation: BLA, MBOC Data collection: CBB, SFAC

Writing the article: BLA Critical revision of the article: ESJO Final approval of the article*: AMK, FHR Statistical analysis: BLA, PBM Overall responsibility: BLA Obtained funding: None

*All authors have read and approved of the final version of the article submitted to J Vasc Bras. 